\title{
Photopatterned Antibodies for Selective Cell Attachment
}

\author{
C. A. Custódio, ${ }^{\dagger}, \S \S$ V. San Miguel-Arranz, ${ }^{\dagger}$ R. A. Gropeanu, ${ }^{\dagger}$ M. Gropeanu, ${ }^{\dagger}$ M. Wirkner, ${ }^{\dagger}$ R. L. Reis, ${ }^{\ddagger}, \S$ \\ J. F. Mano, ${ }^{*}, \S$ and A. del Campo $* \dagger$ \\ ${ }^{\dagger}$ Max-Planck-Institut für Polymerforschung, Ackermannweg 10, 55128 Mainz, Germany \\ \#3B’s Research Group - Biomaterials, Biodegradables and Biomimetics, University of Minho, AvePark, Zona Industrial da Gandra, S. \\ Cláudio do Barco, 4806-909 Caldas das Taipas - Guimaráes, Portugal \\ 33-ICVS/3B’s, PT Government Associated Laboratory, Braga/Guimaráes, Portugal \\ Supporting Information
}

ABSTRACT: We present a phototriggerable system that allows for the spatiotemporal controlled attachment of selected cell types to a biomaterial using immobilized antibodies that specifically target individual cell phenotypes. $o$-Nitrobenzyl caged biotin was used to functionalize chitosan membranes and mediate site-specific coupling of streptavidin and biotinylated antibodies after light activation. The ability of this system to capture and immobilize specific cells on a surface was tested using endothelial-specific biotinylated antibodies and nonspecific ones as controls. Homogeneous patterned monolayers of human umbilical vein endothelial cells were obtained on CD31-functionalized surfaces. This is a simple and generic approach that is applicable to other ligands, materials, and cell types and shows the flexibility of caged ligands to trigger and control the interaction between cells and biomaterials.

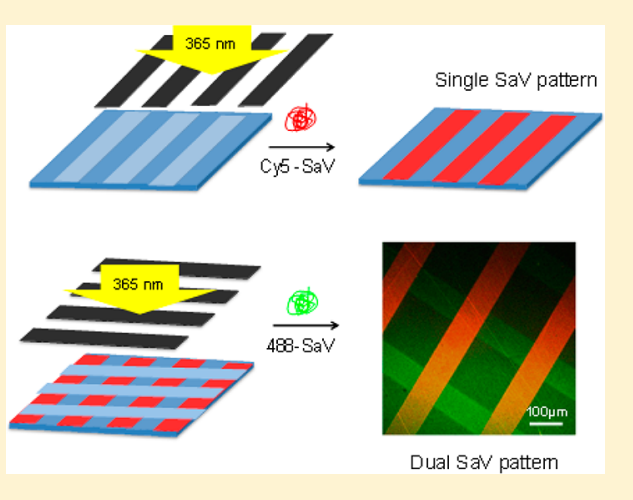

\section{INTRODUCTION}

Cell micropatterns are useful tools for in vitro cell studies and allow high-throughput analysis in biomedical research, including drug screening and tissue engineering. ${ }^{1-3}$ Various microfabrication techniques have been explored for patterning cells on surfaces, including microchannels, ${ }^{4-6}$ microcontact printing, ${ }^{7,8}$ and photolithography. ${ }^{9-11}$ Typically, these methods generate microregions with different hydrophilicities ${ }^{12,13}$ or chemical reactivities on a substrate which might be further functionalized to promote cell attachment.

Cells have also been patterned by using photosensitive layers containing photoactivatable surface-coupling agents ${ }^{14,15}$ or photoactivatable cell adhesion ligands. ${ }^{16-18}$ Light is an attractive stimulus because it can be precisely manipulated in time and space. There are a variety of light-induced reactions by which the chemical function can be modulated. ${ }^{19-22}$ Among them, photoremovable protecting groups (PRPG) are particularly interesting candidates for achieving light-based remote control of the chemical properties of a substrate. A PRPG is a chromophore that can be covalently attached to an organic functionality and inactivates its reactivity. ${ }^{23,24}$ Upon light exposure, the covalent bond is photocleavaged and the reactivity is restored. When PPRG is incorporated into functional groups on biomaterials, light control of biofunctionalization is achieved. ${ }^{22,25}$ Among various classes of photocages, the $o$-nitrobenzyl moiety and its derivatives are the most commonly used ones for biological applications and surface patterning. ${ }^{20-22,26-31}$

A common strategy for immobilizing biomolecules onto surfaces is by taking advantage of the strong interaction between streptavidin $(\mathrm{SaV})$ and biotin, which form a highaffinity complex. ${ }^{32-34}$ A photoactivatable biotin derivative (caged biotin) based on nitrobenzyl photochemistry has been previously described and used for the covalent derivatization of aminopropylsilanized glass or polystyrene surfaces. ${ }^{35-39}$ Here we explore the use of $o$-nitrobenzyl caged biotin to modify a biopolymer (chitosan) and mediate the site-specific coupling of $\mathrm{SaV}$ and biotinylated molecules after light activation. We focus our studies on the attachment of biotinylated antibodies that address individual cell phenotypes and explore the potential of this approach for their specific capture and attachment. The ability to control the locations of specific cell types on a surface offers interesting opportunities for biomedical applications and diagnostics.

\section{EXPERIMENTAL SECTION}

Synthesis of Caged Biotin. Methylnitropiperonyloxycarbonylbiotin was synthesized by adapting a previously reported protocol. ${ }^{36,40}$ See the Supporting Information for details.

Chitosan Film Preparation. Chitosan (Sigma-Aldrich, product no. 448877 , medium molecular weight, $75-85 \%$ deacetylated) was dissolved in a $2 \% \mathrm{v} / \mathrm{v}$ aqueous acetic acid solution to a final concentration of $1 \%(\mathrm{w} / \mathrm{v})$. The solution was degassed under vacuum in a desiccator for $10 \mathrm{~min}$ to remove bubbles from stirring. This solution $(150 \mu \mathrm{L})$ was cast onto glass coverslips (13 $\mathrm{mm}$ in diameter) and dried for $48 \mathrm{~h}$ at room temperature. Subsequently, films were

Received: January 15, 2014

Revised: July 24, 2014

Published: July 30, 2014 


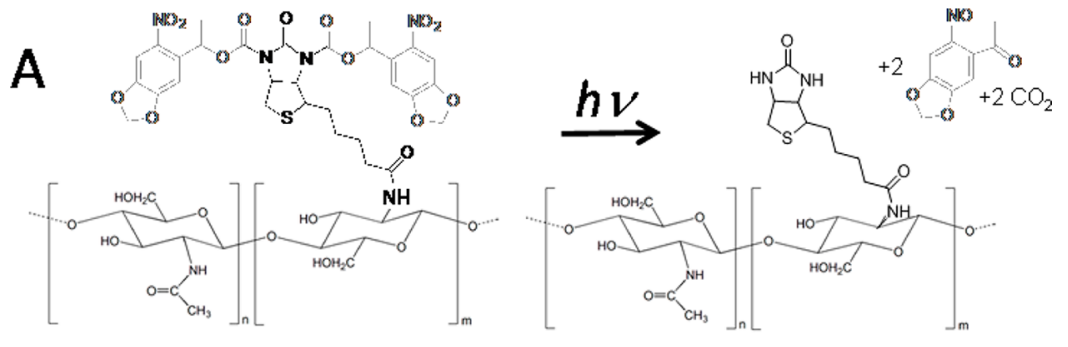

B

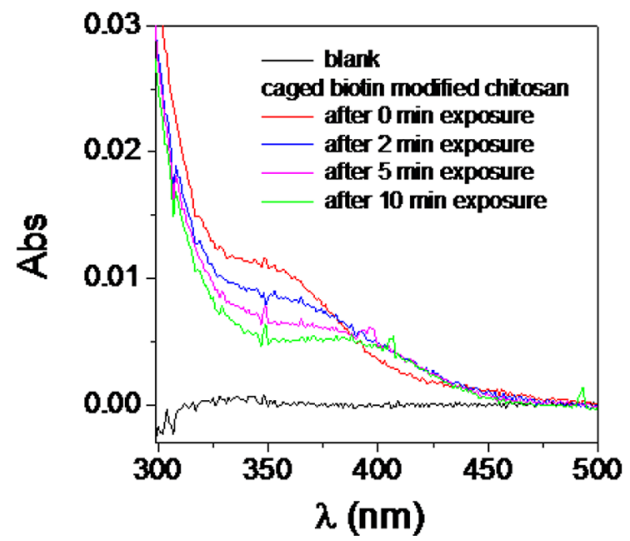

Figure 1. (A) Chemical structure of caged-biotin-functionalized chitosan and the photolytic reaction including the photolysis byproduct. (B) UV spectra of a chitosan film modified with caged biotin before and after light exposure for increasing time.

neutralized with $0.1 \mathrm{M} \mathrm{NaOH}$ for 10 min and washed with water before use.

Functionalization of Chitosan Films with Caged Biotin. Caged biotin $(1 \mathrm{mg})$ was dissolved in $500 \mu \mathrm{L}$ of a $1: 1$ mixture of tetrahydrofuran (THF) and ethanol (EtOH). An aqueous solution $(500 \mu \mathrm{L})$ of $0.2 \mathrm{M}$ EDC ( $N$-(3-(dimethylamino)propyl)- $N^{\prime}$-ethylcarbodiimide hydrochloride), 0.1 M NHS (N-hydroxysuccinimide),

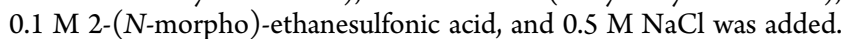
This solution $(150 \mu \mathrm{L})$ was dropped on the chitosan film and incubated for $3 \mathrm{~h}$. After that time, the chitosan film was washed with $\mathrm{EtOH}$ and Mili-Q water and dried gently in a stream of nitrogen.

UV-Vis Spectrometry of Caged-Biotin-Functionalized Films. UV spectra (on a Varian Cary 4000 UV-vis spectrometer) of chitosan films cast on quartz substrates and modified with caged biotin were recorded before and after irradiation using an LED (LTPR36 from Opto Engineering, $1.35 \mathrm{~mW} \mathrm{~cm}{ }^{-2}, 365 \mathrm{~nm}$ ) for uncaging. UV spectra were recorded on a Varian Cary $4000 \mathrm{UV}$-vis spectrometer (Varian Inc., Palo Alto, CA) for qualitative analysis of the immobilization process.

Generation of Surface Patterns. Patterns with uncaged and caged-biotin sites were obtained by light irradiation of chitosanmodified films using an LED (M365L2, Thorlabs, $1.2 \mathrm{~mW} \mathrm{~cm}{ }^{-2}, 365$ $\mathrm{nm}$ ) for $7 \mathrm{~min}$ through a gold/chrome mask with $100 \mu \mathrm{m}$ stripes spaced $200 \mu \mathrm{m}$ apart and $10 \times 10 \mu \mathrm{m}^{2}$ squares. Substrates were rinsed with THF and Milli- $Q$ water to remove photolysis products from the surface layer. The patterned biotin substrates were incubated for 30 min with Cy5-labeled SaV (eBioscience, $10 \mu \mathrm{L} / \mathrm{mL}$ ) or DyLight 488 SaV (Biolegend, $5 \mu \mathrm{L} / \mathrm{mL}$ ) in PBS, followed by washing in PBS. The surface patterns were imaged using a fluorescence microscope (Olympus Fluoview FV300).

The antibody patterns were obtained by incubating masked, exposed caged-biotin substrates in purified $\mathrm{SaV}(10 \mu \mathrm{g} / \mathrm{mL})$ for 90 min, washing with PBS, and finally incubating with antihuman CD31Biotin (eBioscience) $(5 \mu \mathrm{g} / \mathrm{mL})$. As a control for the nonspecific binding of the biotinylated antibody, a set of samples was not incubated with $\mathrm{SaV}$, i.e., the irradiation step was followed by a washing step and finally samples were incubated with antihuman CD31-Biotin (eBioscience, $5 \mu \mathrm{g} / \mathrm{mL}$ ). All samples were then incubated with Alexa Fluor 488-antimouse IgG $(2.5 \mu \mathrm{g} / \mathrm{mL})$ (Molecular Probes) for $5 \mathrm{~min}$.
The surface patterns were imaged using a confocal laser scanning microscope (Olympus Fluoview FV300).

Cell Experiments. Human umbilical vein endothelial cells (HUVECs) were maintained in M-199 medium (Sigma, USA) supplemented with sodium bicarbonate, $1 \%$ antibiotic/antimycotic, $20 \%$ FBS, $0.34 \%$ glutamax (Gibco), $50 \mu \mathrm{g} / \mathrm{mL}$ endothelial cell growth supplement (ECGS, BD Biosciences), and $50 \mu \mathrm{g} / \mathrm{mL}$ heparin (Sigma).

Biotin-modified surfaces after masked irradiation were sterilized in $70 \%$ ethanol and washed extensively with sterile PBS before cell culturing. The irradiated substrates were incubated with $\mathrm{SaV}(10 \mu \mathrm{g} /$ $\mathrm{mL}$ ) for $30 \mathrm{~min}$, washed with $\mathrm{PBS}$, and incubated with biotinylated antihuman CD31 and antihuman CD90 (eBioscience). Cells were seeded onto the surfaces at a density of $5 \times 10^{4}$ cells $/ \mathrm{cm}^{2}$. Phase contrast microscope images were obtained by phase contrast (Zeiss, Axiovert 40). At specific time points, samples were fixed with formalin, incubated with phalloidin-tetramethylrhodamine B isothiocyanate (Sigma) for $45 \mathrm{~min}$ to visualize the cytoskeletal filaments, and incubated with DAPI (4,6-diamidino-2-phenylindole, dilactate; Invitrogen) for $5 \mathrm{~min}$ to visualize the nucleus.

Representative fluorescent images were acquired using the Axioplan Imager Z1 fluorescence microscope (Zeiss, Axio Imager Z1m) using laser lines 405 and 594 for DAPI and phalloidin, respectively.

\section{RESULTS AND DISCUSSION}

Functionalization and Photochemical Activation of the Surface. Caged biotin consists of a biotin molecule modified with two methylnitropiperonyloxycarbonyl photoremovable protecting groups at the $\mathrm{N}-1^{\prime}$ - and $\mathrm{N}-3^{\prime}$ positions that inactivate binding to $\mathrm{SaV}^{35-37}$ The free carboxylic group of caged biotin was used to attach it to the amine groups of chitosan films using EDC/NHS activation (Figure 1A). The coupling of the caged biotin to the surface was proven by UV spectroscopy. Figure 1B shows the UV spectra of the cagedbiotin-modified chitosan film. The absorbance maximum at around $350 \mathrm{~nm}$ confirmed the presence of the methylnitropiperonyloxycarbonyl chromophore. 

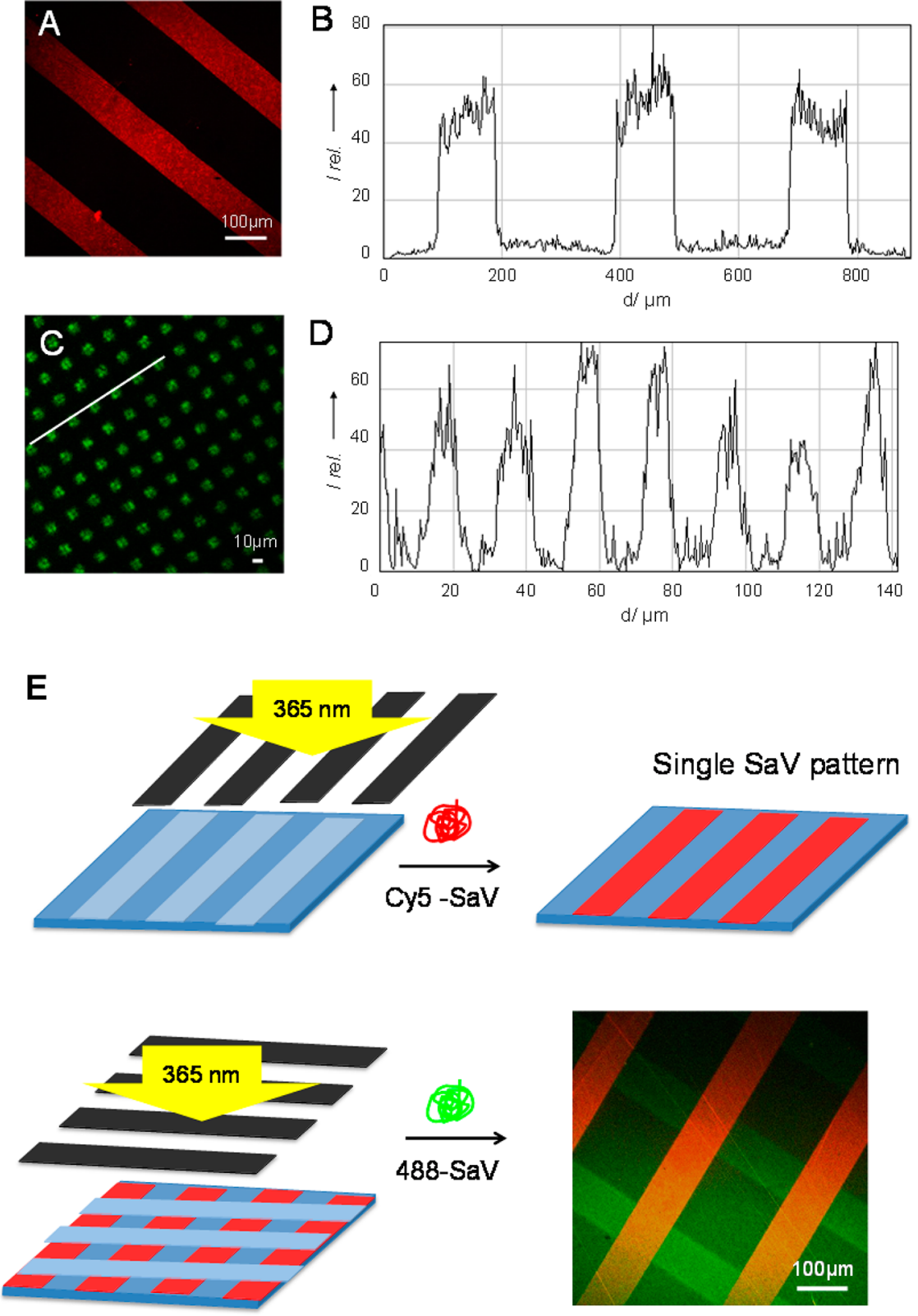

Dual SaV pattern

Figure 2. (A) Fluorescence image of Cy5-SaV on patterned stripes of $100 \mu \mathrm{m}$ width of activated biotin. (B) Intensity profile of Cy5-SaV on patterned stripes of $100 \mu \mathrm{m}$ width of activated biotin. (C) Fluorescence image of DyLight488-SaV on patterned $10 \times 10 \mu \mathrm{m}^{2}$ squares. (D) Intensity profile of DyLight $488-\mathrm{SaV}$ on patterned $10 \times 10 \mu \mathrm{m}^{2}$ squares of fluorescently labeled SaV. (E) Fluorescent image of the two-color SaV pattern after sequential patterning and site-selective immobilization of Cy5- and DyLight488-SaV by successive light exposure and incubation steps.

The photolysis mechanism of $o$-nitrobenzyl derivatives has been extensively studied and reported, and the expected photoproducts are represented in Figure $1 \mathrm{~B}^{20-22,41-43}$ The photolysis of the chromophore in the caged-biotin-functionalized film was investigated by UV spectroscopy. A clear decrease in the absorbance of $\lambda_{\max } \approx 350 \mathrm{~nm}$ and an increase in absorbance at longer wavelengths with increasing light exposure time were observed. These changes have been associated with the appearance of the nitroso photoproduct and confirm that photolysis has taken place. $^{20,21}$

Protein and Antibody Micropatterns. In order to test the functionality of the chitosan-immobilized biotin after uncaging, caged-biotin-modified chitosan films were irradiated through a mask containing quartz/chrome microfeatures. In the exposed areas, the caged biotin is expected to be uncaged (i.e., activated). In the nonexposed areas, caged biotin is expected to retain its latent functionality. In a subsequent coupling step with fluorescently labeled $\mathrm{SaV}$ (Cy5-SaV or DyLight $488-\mathrm{SaV}$ ), we tested the site-selective attachment of the protein to the uncaged regions. Figure 2A,C shows the fluorescence images of the chitosan films on substrates previously irradiated through a mask with chrome stripes of $100 \mu \mathrm{m}$ spaced by $200 \mu \mathrm{m}$ and squares of $10 \times 10 \mu \mathrm{m}^{2}$, respectively. Fluorescence imaging of the surfaces showed that only the exposed areas (uncaged biotin) become bright due to the coupling of labeled $\mathrm{SaV}$. This result demonstrates the bioactivity of the uncaged biotin and the validity of this approach for patterning protein layers. The fluorescence intensity profiles (Figure 2B,D) evidenced high 

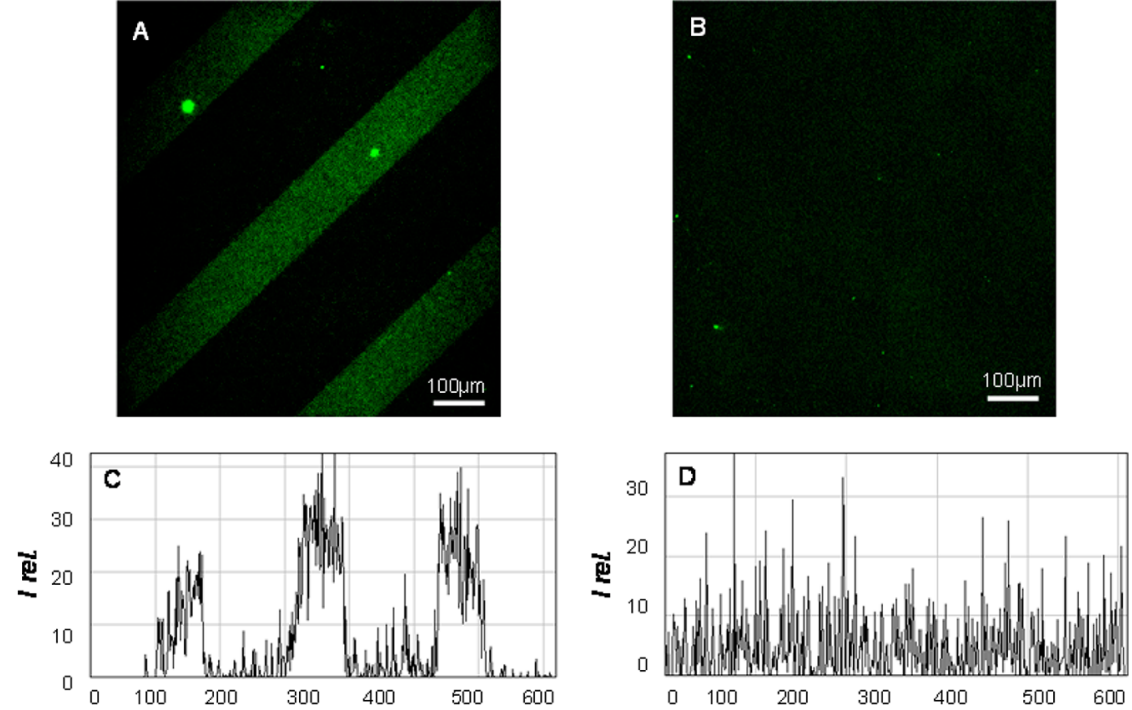

Figure 3. (A) Fluorescence image and intensity profile of antibody patterns on masked irradiated caged-biotin-modified chitosan films after incubation with $\mathrm{SaV}, \mathrm{CD} 31$-biotin antibody, and Alexa Fluor 488-antimouse IgG. (B) Negative control where the surface was not incubated with SaV. (C, D) Profiles of the fluorescence intensity.
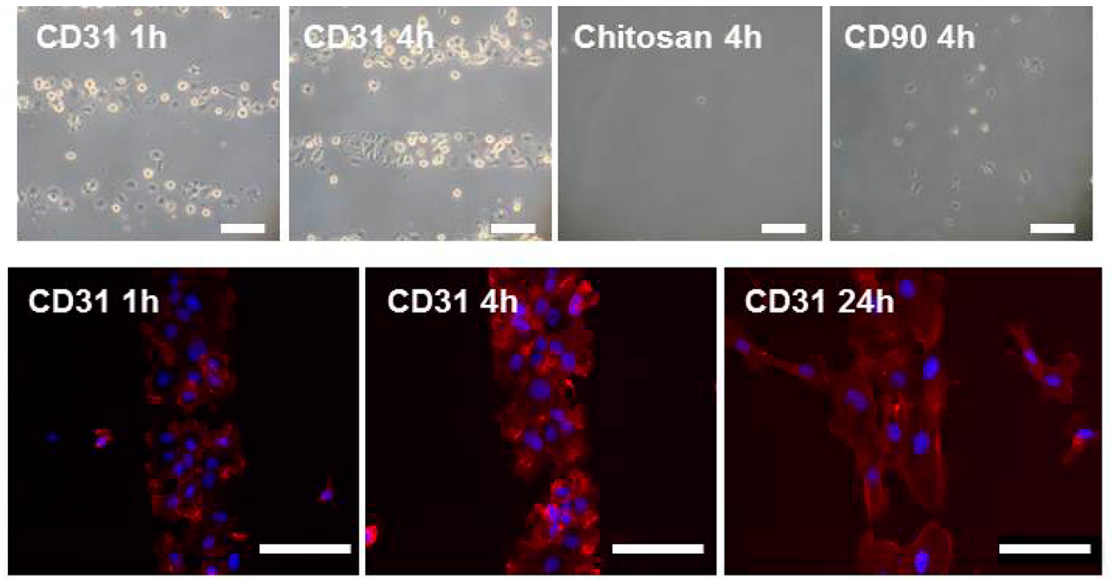

Figure 4. Micropatterns of HUVECs on chitosan films formed by the selective recognition of immobilized antibodies. (Top row) Phase contrast microscope images. (Bottom row) Fluorescent microscope images of patterned cells stained with DAPI (blue) and phalloidin (red). Scale bars: 100 $\mu \mathrm{m}$.

contrast between the exposed and nonexposed regions, indicating high selectivity of the protein coupling. Within the exposed areas, the fluorescence was less homogeneous than expected. This is attributed to the roughness of the chitosan film that results from the film processing steps (casting and neutralization). This issue can be improved using other types of hydrogels that allow more homogeneous film preparation by spin coating.

We further checked if this approach could be used to immobilize more than one protein type on different sites of the same substrate after a sequence of light exposure and incubation steps (Figure 2E). Biotin-functionalized chitosan films were irradiated through a stripped pattern $(100 \mu \mathrm{m}$ stripes spaced $200 \mu \mathrm{m}$ apart) and then incubated with Cy5-labeled $\mathrm{SaV}$. In a second patterning step, the photomask was rotated $90^{\circ}$, and the sample was irradiated again and then incubated with DyLight $488 \mathrm{SaV}$. Well-defined patterns with two different colors were obtained, indicating efficient and preferential $\mathrm{SaV}$ binding to the uncaged biotin units at the exposed surfaces. The pattern obtained at the second incubation step (green lines,
Figure 2E) showed a lower contrast than the pattern obtained after the first light exposure and incubation steps (expected red lines became orange due to the presence of a green fluorophore). This is a sign of the nonspecific interaction of the fluorescent molecules with the biotinylated chitosan, which can be attributed to a partial loss of the protein-repelling properties of chitosan with increasing washing/coupling steps.

These results demonstrate the sequential light-triggered release of the protecting group from caged biotin and the generation of functional biotin at the surface for $\mathrm{SaV}$ binding with spatial and temporal resolution. Spatial control of the light-activation step is transferred from the photoactivatable biotin patterns to the $\mathrm{SaV}$ immobilization.

We next tested if this approach could be applied to the controlled immobilization of biotinylated antibodies on the patterned $\mathrm{SaV}$ layer. $\mathrm{SaV}$ patterns were incubated with biotinylated antibody CD31, a $130-\mathrm{kDa}$ membrane-spanning glycoprotein that is part of the panel of endothelial-cellassociated markers. ${ }^{44,45}$ To visualize the conjugation of CD31 to the surface, a second incubation step with secondary 
fluorescent antibody Alexa Fluor 488 antimouse was performed. Clear fluorescent patterns were observed (Figure 3A), demonstrating the site selective and functional immobilization of CD31 antibody mediated by the uncaged biotin-SaV patterns, whereas no fluorescence was detected on the negative control (Figure 3B), i.e., surfaces not incubated with SaV.

Cell Micropatterns via Recognition of Surface-Immobilized Antibodies on Caged-Biotin Patterns. The obtained antibody patterns were used to isolate and recruit specific cell types in patterned areas. For this purpose, masked irradiated caged-biotin-functionalized chitosan films were incubated with purified $\mathrm{SaV}$ followed by an incubation step with biotinylated antibody CD31. Patterned stripes of $100 \mu \mathrm{m}$ width functionalized with CD31 and separated by $200 \mu \mathrm{m}$ regions of caged biotin were obtained. CD31 is an endothelial cell-associated marker that can be used to selectively target endothelial cells. Surfaces functionalized with the CD90 antibody were also prepared as negative controls. CD90 is a glycosylphosphatidylinositol-anchored glycoprotein that is highly expressed in many cell types such as neurons, thymocytes, fibroblasts, or mesenchymal stem cells but not expressed on the surface of nonactivated endothelial cells. ${ }^{46}$ Primary endothelial cells (HUVECs) were seeded on antihuman CD31- or antihuman CD90-functionalized surfaces and on plain chitosan as controls. Cells were attached to the CD31functionalized areas after $1 \mathrm{~h}$ of incubation in a highly selective manner, revealing the stripes of the underlying CD31 pattern (Figure 4). The pattern was clearly visible after $4 \mathrm{~h}$ of incubation, and cells remained confined to the areas functionalized with the specific antibody (Figure 4). Endothelial cells did not attach to plain chitosan or chitosan functionalized with CD90, indicating that the attachment was mediated only by the recognition of immobilized antihuman CD31. The fluorescence analysis of the attached cells showed spreading and alignment of the cell membrane along the edge of the micropattern (Figure 4). It is important to note that caged biotin has been applied to obtain protein patterns in earlier studies. ${ }^{35-37}$ Here we demonstrate that this approach can be further extended to pattern biotinylated antibodies via $\mathrm{SaV}$ on a biopolymeric surface and apply it for selective cell attachment.

\section{CONCLUSIONS}

Chitosan surfaces chemically modified with caged biotin allow light-driven patterning of antibodies to recruit and attach specific cell types at predefined positions on a surface. In contrast to photosensitive derivatives of RGD cell-adhesive peptide, which is typically used to obtain cell patterns, lighttriggered cell attachment using antibodies allows specific targeting of phenotypes. This is an important issue for implantable materials, where the recruitment of specific cell types from surrounding tissues in vivo is crucial to the regeneration process. It is also important in coculture systems, where different cell types from a mixed cell population need to be recruited to selected areas, and this might be achieved by the recognition of a preimmobilized specific antibody. The versatility of this method allows functionalization with any biotinylated molecule as antibodies, growth factors, or peptides of interest.

\section{ASSOCIATED CONTENT}

\section{Supporting Information}

The description of the synthesis of caged biotin. This material is available free of charge via the Internet at http://pubs.acs. org/.

\section{AUTHOR INFORMATION}

\section{Corresponding Authors}

*Tel: +351-253510904. E-mail: jmano@dep.uminho.pt.

*Tel: +49 6131 379-563. E-mail: delcampo@mpip-mainz.mpg. de.

\section{Notes}

The authors declare no competing financial interest.

\section{ACKNOWLEDGMENTS}

We thank Martina Knecht (MPIP) for help with the synthesis of caged biotin and Dr. Ron Unger and Prof. C. J. Kirkpatrick (University Clinic Mainz, RepairLab) for providing HUVECs. C.A.C. acknowledges funding support from the Portuguese Foundation for Science and Technology (FCT) (fellowship SFRH/BD/61390/2009) and from the International MaxPlanck Research School in Mainz. The research leading to these results has received funding from the European Union's Seventh Framework Programme (FP7/2007-2013) under grant agreement no. REGPOT-CT2012-316331-POLARIS.

\section{REFERENCES}

(1) Falconnet, D.; Csucs, G.; Grandin, H. M.; Textor, M. Surface engineering approaches to micropattern surfaces for cell-based assays. Biomaterials 2006, 27, 3044-63.

(2) Fink, J.; Thery, M.; Azioune, A.; Dupont, R.; Chatelain, F.; Bornens, M.; Piel, M. Comparative study and improvement of current cell micro-patterning techniques. Lab Chip 2007, 7, 672-680.

(3) Vedula, S. R. K.; Leong, M. C.; Lai, T. L.; Hersen, P.; Kabla, A. J.; Lim, C. T.; Ladoux, B. Emerging modes of collective cell migration induced by geometrical constraints. Proc. Natl. Acad. Sci. U.S.A. 2012, 109, 12974-12979.

(4) Yu, H. M.; Meyvantsson, I.; Shkel, I. A.; Beebe, D. J. Diffusion dependent cell behavior in microenvironments. Lab Chip 2005, 5, 1089-1095.

(5) Ku, S. H.; Lee, J. S.; Park, C. B. Spatial Control of Cell Adhesion and Patterning through Mussel-Inspired Surface Modification by Polydopamine. Langmuir 2010, 26, 15104-15108.

(6) Kaigala, G. V.; Lovchik, R. D.; Delamarche, E. Microfluidics in the "Open Space" for Performing Localized Chemistry on Biological Interfaces. Angew. Chem. Int. Edit 2012, 51, 11224-11240.

(7) Lehnert, D.; Wehrle-Haller, B.; David, C.; Weiland, U.; Ballestrem, C.; Imhof, B. A.; Bastmeyer, M. Cell behaviour on micropatterned substrata: limits of extracellular matrix geometry for spreading and adhesion. J. Cell Sci. 2004, 117, 41-52.

(8) Custodio, C. A.; Frias, A. M.; del Campo, A.; Reis, R. L.; Mano, J. F. Selective Cell Recruitment and Spatially Controlled Cell Attachment on Instructive Chitosan Surfaces Functionalized with Antibodies. Biointerphases 2012, 7 (1-4).

(9) Falconnet, D.; Koenig, A.; Assi, T.; Textor, M. A combined photolithographic and molecular-assembly approach to produce functional micropatterns for applications in the biosciences. Adv. Funct Mater. 2004, 14, 749-756.

(10) Lee, J. Y.; Shah, S. S.; Zimmer, C. C.; Liu, G. Y.; Revzin, A. Use of photolithography to encode cell adhesive domains into protein microarrays. Langmuir 2008, 24, 2232-2239.

(11) Sasaki, D.; Shimizu, T.; Masuda, S.; Kobayashi, J.; Itoga, K.; Tsuda, Y.; Yamashita, J. K.; Yamato, M.; Okano, T. Mass preparation of size-controlled mouse embryonic stem cell aggregates and induction of cardiac differentiation by cell patterning method. Biomaterials 2009, 30, 4384-4389. 
(12) Oliveira, M. B.; Salgado, C. L.; Song, W. L.; Mano, J. F. Combinatorial On-Chip Study of Miniaturized 3D Porous Scaffolds Using a Patterned Superhydrophobic Platform. Small 2013, 9, 768778 .

(13) Efremov, A. N.; Stanganello, E.; Welle, A.; Scholpp, S.; Levkin, P. A. Micropatterned superhydrophobic structures for the simultaneous culture of multiple cell types and the study of cell-cell communication. Biomaterials 2013, 34, 1757-1763.

(14) Dillmore, W. S.; Yousaf, M. N.; Mrksich, M. A photochemical method for patterning the immobilization of ligands and cells to selfassembled monolayers. Langmuir 2004, 20, 7223-7231.

(15) Kikuchi, Y.; Nakanishi, J.; Shimizu, T.; Nakayama, H.; Inoue, S.; Yamaguchi, K.; Iwai, H.; Yoshida, Y.; Horiike, Y.; Takarada, T.; Maeda, M. Arraying Heterotypic Single Cells on Photoactivatable CellCulturing Substrates. Langmuir 2008, 24, 13084-13095.

(16) Wirkner, M.; Weis, S.; San Miguel, V.; Alvarez, M.; Gropeanu, R. A.; Salierno, M.; Sartoris, A.; Unger, R. E.; Kirkpatrick, C. J.; del Campo, A. Photoactivatable Caged Cyclic RGD Peptide for Triggering Integrin Binding and Cell Adhesion to Surfaces. Chembiochem 2011, $12,2623-2629$.

(17) Goulet-Hanssens, A.; Sun, K. L. W.; Kennedy, T. E.; Barrettt, C. J. Photoreversible Surfaces to Regulate Cell Adhesion. Biomacromolecules 2012, 13, 2958-2963.

(18) Salierno, M. J.; Garcia, A. J.; del Campo, A. Photo-Activatable Surfaces for Cell Migration Assays. Adv. Funct Mater. 2013, 23, 59745980.

(19) Kanoh, N.; Kumashiro, S.; Simizu, S.; Kondoh, Y.; Hatakeyama, S.; Tashiro, H.; Osada, H. Immobilization of natural products on glass slides by using a photoaffinity reaction and the detection of proteinsmall-molecule interactions. Angew. Chem. Int. Edit 2003, 42, 55845587.

(20) Alonso, J. M.; Reichel, A.; Piehler, J.; del Campo, A. Photopatterned surfaces for site-specific and functional immobilization of proteins. Langmuir 2008, 24, 448-457.

(21) Alvarez, M.; Alonso, J. M.; Filevich, O.; Bhagawati, M.; Etchenique, R.; Piehler, J.; del Campo, A. Modulating Surface Density of Proteins via Caged Surfaces and Controlled Light Exposure. Langmuir 2011, 27, 2789-2795.

(22) Cui, J. X.; Wang, M.; Zheng, Y. J.; Muniz, G. M. R.; del Campo, A. Light-Triggered Cross-Linking of Alginates with Caged Ca2+. Biomacromolecules 2013, 14, 1251-1256.

(23) Pelliccioli, A. P.; Wirz, J. Photoremovable protecting groups: reaction mechanisms and applications. Photoch Photobio Sci. 2002, 1, $441-458$.

(24) Ellis-Davies, G. C. R. Caged compounds: photorelease technology for control of cellular chemistry and physiology. Nat. Methods 2007, 4, 619-628.

(25) Wylie, R. G.; Shoichet, M. S. Three-Dimensional Spatial Patterning of Proteins in Hydrogels. Biomacromolecules 2011, 12, 3789-3796.

(26) Klan, P.; Solomek, T.; Bochet, C. G.; Blanc, A.; Givens, R.; Rubina, M.; Popik, V.; Kostikov, A.; Wirz, J. Photoremovable Protecting Groups in Chemistry and Biology: Reaction Mechanisms and Efficacy. Chem. Rev. 2013, 113, 119-191.

(27) Grunwald, C.; Schulze, K.; Reichel, A.; Weiss, V. U.; Blaas, D.; Piehler, J.; Wiesmuller, K. H.; Tampe, R. In situ assembly of macromolecular complexes triggered by light. P Natl. Acad. Sci. USA 2010, 107, 6146-6151.

(28) Bhagawati, M.; Lata, S.; Tampe, R.; Piehler, J. Native Laser Lithography of His-Tagged Proteins by Uncaging of Multivalent Chelators. J. Am. Chem. Soc. 2010, 132, 5932-+.

(29) Gatterdam, V.; Stoess, T.; Menge, C.; Heckel, A.; Tampe, R. Caged Glutathione - Triggering Protein Interaction by Light. Angew. Chem. Int. Edit 2012, 51, 3960-3963.

(30) Laboria, N.; Wieneke, R.; Tampe, R. Control of Nanomolar Interaction and In Situ Assembly of Proteins in Four Dimensions by Light. Angew. Chem. Int. Edit 2013, 52, 848-853.

(31) Gatterdam, V. R. R.; Stoess, T.; Fichte, M.; Wachtveitl, J.; Heckel, A.; Tampé, R. Three-Dimensional Protein Networks
Assembled by Two-Photon Activation. Angew. Chem. Int. Edit 2014, 53, 5680-5684

(32) Vermette, P.; Gengenbach, T.; Divisekera, U.; Kambouris, P. A.; Griesser, H. J.; Meagher, L. Immobilization and surface characterization of NeutrAvidin biotin-binding protein on different hydrogel interlayers. J. Colloid Interface Sci. 2003, 259, 13-26.

(33) Laitinen, O. H.; Hytonen, V. P.; Nordlund, H. R.; Kulomaa, M. S. Genetically engineered avidins and streptavidins. Cell. Mol. Life Sci. 2006, 63, 2992-3017.

(34) You, C.; Bhagawati, M.; Brecht, A.; Piehler, J. Affinity capturing for targeting proteins into micro and nanostructures. Anal Bioanal Chem. 2009, 393 (6-7), 1563-1570.

(35) Sandberg, S. A.; Barrett, R. W.; Pirrung, M.; Lu, A. L.; Kiangsoontra, B.; Holmes, C. P. Spatially-Addressable Immobilization of Macromolecules on Solid Supports. J. Am. Chem. Soc. 1995, 117, 12050-12057.

(36) Hengsakul, M.; Cass, A. E. G. Protein patterning with a photoactivatable derivative of biotin. Bioconjugate Chem. 1996, 7, 249254.

(37) Choi, H. J.; Kim, N. H.; Chung, B. H.; Seong, G. H. Micropatterning of biomolecules on glass surfaces modified with various functional groups using photoactivatable biotin. Anal. Biochem. 2005, 347, 60-66.

(38) Terai, T.; Maki, E.; Sugiyama, S.; Takahashi, Y.; Matsumura, H.; Mori, Y.; Nagano, T. Rational Development of Caged-Biotin ProteinLabeling Agents and Some Applications in Live Cells. Chem. Biol. 2011, 18, 1261-1272.

(39) Blawas, A. S.; Oliver, T. F.; Pirrung, M. C.; Reichert, W. M. Step-and-repeat photopatterning of protein features using caged/ biotin-BSA: Characterization and resolution. Langmuir 1998, 14, $4243-4250$.

(40) Pirrung, M. C.; Huang, C. Y. A general method for the spatially defined immobilization of biomolecules on glass surfaces using "caged" biotin. Bioconjugate Chem. 1996, 7, 317-321.

(41) Zhu, Q. Q.; Schnabel, W.; Schupp, H. Formation and Decay of Nitronic Acid in the Photorearrangement of Ortho-Nitrobenzyl Esters. J. Photochem. 1987, 39, 317-332.

(42) Schupp, H.; Wong, W. K.; Schnabel, W. Mechanistic Studies of the Photorearrangement of Ortho-Nitrobenzyl Esters. J. Photochem. 1987, 36, 85-97.

(43) Il'ichev, Y. V.; Schworer, M. A.; Wirz, J. Photochemical reaction mechanisms of 2-nitrobenzyl compounds: Methyl ethers and caged ATP. J. Am. Chem. Soc. 2004, 126, 4581-4595.

(44) Newman, P. J.; Berndt, M. C.; Gorski, J.; White, G. C.; Lyman, S.; Paddock, C.; Muller, W. A. Pecam-1 (Cd31) Cloning and Relation to Adhesion Molecules of the Immunoglobulin Gene Superfamily. Science 1990, 247, 1219-1222.

(45) Albelda, S. M.; Muller, W. A.; Buck, C. A.; Newman, P. J. Molecular and Cellular Properties of Pecam-1 (Endocam/Cd31) - a Novel Vascular Cell Cell-Adhesion Molecule. J. Cell Biol. 1991, 114, $1059-1068$

(46) Kisselbach, L.; Merges, M.; Bossie, A.; Boyd, A. CD90 Expression on human primary cells and elimination of contaminating fibroblasts from cell cultures. Cytotechnology 2009, 59, 31-44. 